\title{
REGIONALIZAÇÃo E ESPACIALIZAÇÃO DE VAZÕES DE PERMANÊNCIA: ESTUDO APLICADO NA BACIA RIO PIRACICABA-MG
}

\author{
MACIEL, Amanda Lopes - amandamaciel.eng@gmail.com \\ Instituto Nacional de Pesquisas Espaciais / INPE \\ VIEIRA, Eliane Maria - elianevieira@unifei.edu.br \\ Universidade federal de Itajubá / UNIFEI
}

\author{
MONTE MOR, Roberto Cézar - rmontemor@unifei.edu.br \\ Universidade federal de Itajubá / UNIFEI
}

\author{
VASQUES, Ana Carolina - ana.freitas@unifei.edu.br \\ Universidade federal de Itajubá / UNIFEI
}

\begin{abstract}
RESUMO: Visando suprir a escassez de informações fluviométricas associada à inconsistência temporal e espacial das séries históricas disponíveis, a regionalização de vazões é uma alternativa para estimar a vazão para regiões desprovidas de estações. Dentre os diversos métodos existentes, um dos mais difundidos é o Método Tradicional (MT), o qual consiste na identificação de regiões hidrologicamente homogêneas e no ajuste de equações de regressão tendo como variáveis parâmetros fisiográficos das bacias. Este método tem sido comumente empregado estimando a vazão por áreas. No entanto, este trabalho tem como objetivo a regionalização das vazões com permanência de $95 \%$ do tempo (Q95) obtida pelo MT, empregando o Sistema de Informação Geográfica a fim de se obtê-las por células no leito dos principais rios da bacia do rio Piracicaba-MG. Para tanto, foram utilizadas dez estações fluviométricas da ANA (Agência Nacional de Águas) instaladas na bacia, considerando apenas aquelas que apresentaram mais de cinco anos de dados com tolerância de $10 \%$ de falhas. A escolha do melhor modelo de regressão foi determinada pela análise do erro relativo e pelo Coeficiente de Eficiência de Nash e Sutcliffe $(-2,84$ e 0,97, respectivamente) empregando como parâmetro de entrada a área de contribuição com um modelo potencial. Para a espacialização das vazões foi gerado o mapa de fluxo acumulado (que corresponde ao cálculo do número de células a montante que contribuem para a célula em questão) e aplicada a equação, assim para cada célula no leito dos principais rios foi obtida a Q95. Embora a metodologia empregada não substitua uma densa rede hidrometeorológica, esta apresentou resultado satisfatório na medida que permitiu a obtenção da Q95 de forma espacializada, inovando ao que tradicionalmente se faz, que seria por área.
\end{abstract}

PALAVRAS-CHAVE: Coeficiente de Eficiência; Geoprocessamento; Método Tradicional; Modelo Potencial.

REGIONALIZATION AND SPATIALIZATION OF DURATION FLOWS: STUDY APPLIED IN THE PIRACICABA-MG RIVER BASIN

ABSTRACT: Aiming to supply the scarcity of fluviometric informations associated with temporal and spatial inconsistency of historical series available, the regionalization of flows is emerging as an alternative to estimate the flow in regions devoid of stations. Among the various existing methods, one of the most widespread is the traditional method (TM), which consists in the identification of hidrologically homogeneous regions and in the adjustment of regression equations having as variables the physiographic parameters of the basins. This method has been commonly employed estimating flow by area. However, the aim of this paper is to regionalize the flows with duration of $95 \%$ of the time (Q95) obtained by the TM, using the Geographic Information System (GIS) in order to obtain them by cells in the bed of the main rivers of the Piracicaba-MG river basin. For this purpose, ten fluviometric stations from ANA (National Water Agency) installed in the basin were used, considering only those that presented more than five years of data with a tolerance of $10 \%$ of failures. The choice of the best regression model 
was determined by the relative error analysis and the Nash and Sutcliffe Efficiency Coefficient ( -2.84 and 0.97 , respectively) using the contribution area as an input parameter with a potential model. For the spatialization of flows, the accumulated flow map (which corresponds to the calculation of the number of upstream cells contributing to the cell in question) was generated and the equation was applied, so for each cell in the bed of the main rivers, Q95 was obtained. Although the methodology employed does not replace a dense hydrometeorological network, this one presented a satisfactory result in the measure that allowed the Q95 to be made available, innovating to what is traditionally done, which would be by area.

KEYWORDS: Coefficient of efficiency; GIS; Traditional Method; Potential Model.

\section{INTRODUÇÃO}

Dentre os maiores desafios vivenciados em hidrologia atualmente, merece destaque a dificuldade em se conhecer adequadamente 0 comportamento dos processos hidrológicos em determinadas regiões. O baixo número de estações existentes na rede hidrometeorológica e a escassa disponibilidade de dados consistentes trazem consigo um grande desafio em se desenvolver estudos e projetos que empregue seus dados, entre estes o de se estabelecer as vazões de referência para dar subsídio à gestão dos recursos hídricos.

Dada a necessidade de suprir a deficiência da rede hidrométrica no Brasil, a regionalização hidrológica de vazões é uma técnica que tem sido utilizada com resultados satisfatórios, visto que a regionalização permite realizar a transferência espacial de informações (PINTO, 2006).

Segundo Pruski et al. (2012), esta técnica relaciona os processos hidrológicos com as características físicas e climáticas de uma bacia.

Para King et al. (2008), existe um vasto conjunto de metodologias formais para estabelecer as vazões ambientais. Segundo os autores, a maioria destas podem ser agrupadas em quatro métodos razoavelmente distintos: hidrológico; hidráulico; holístico e de simulação de habitat. Existem também uma série de abordagens híbridas que compreendem elementos de um ou mais desses tipos de metodologia.

Em relação aos métodos hidrológicos, de acordo com Naghettini e Pinto (2007), eles podem ser divididos em três classes: métodos de regionalização dos parâmetros da distribuição de probabilidades, métodos de regionalização do evento com um determinado risco e métodos de regionalização da curva adimensional de frequências.

Tucci (2002) apresenta vários métodos para a regionalização de vazões de frequência. Dentre estes métodos, um dos métodos mais difundidos para a regionalização de vazões é o Método Tradicional (MT). Este consiste na identificação de regiões hidrologicamente homogêneas e no ajuste de equações de regressão entre as diferentes variáveis a serem regionalizadas e as características físicas e climáticas das bacias de drenagem para cada região homogênea (NOVAES, 2005).

Visto isso, uma das etapas importantes no processo é a seleção das variáveis explicativas da variável a regionalizar (ANDRADE; HAWKINS, 2000). Assim, uma das tecnologias que possibilitam a caracterização física de uma região é denominada geotecnologia, as quais possibilitam a aquisição e 
modelagem de informações espaciais implementadas por sistema computacional de geoprocessamento (CATELANI, 2015).

Diante do exposto, o presente trabalho tem por objetivo apresentar uma metodologia a ser desenvolvida em ambiente SIG (Sistemas de Informações Geográficas) de forma espacializada, para a obtenção da vazão mínima Q_95, ao longo dos cursos hídricos, empregando-se a regionalização dos dados de vazão da bacia hidrográfica do rio Piracicaba, totalmente inserida no estado de Minas Gerais. Estudos desta natureza são de fundamental importância uma vez que a vazão representa a resposta da bacia as alterações climáticas, tais como os eventos extremos de precipitação, e antrópicas, relacionadas a mudanças do uso e ocupação do solo, além de contribuírem para um melhor planejamento e gestão dos recursos hídricos, que é essencial para o desenvolvimento sustentável de uma região.

\section{PROCEDIMENTO METOdOLÓGico}

A bacia de estudo deste trabalho pertencente à bacia do rio Doce, sendo uma das seis Unidades de Planejamento e Gestão de Recursos Hídricos (UPGRH) desta. A bacia ocupa uma área de aproximadamente $5.438,88 \mathrm{Km}^{2}$, abrangendo 21 municípios mineiros, da qual aproximadamente $35,92 \%$ de sua extensão está inserida em Itabira (Figura 1).

O clima da bacia do rio Piracicaba é considerado de transição, pois recebe influência de sua posição latitudinal, dos fenômenos meteorológicos das latitudes médias e tropicais ( $A^{\prime} B$ SABER, 2003). Encontram-se na bacia três variações climáticas: clima AW ou tropical, clima CWa ou mesotérmico de verões quentes e o clima $\mathrm{CWb}$ ou mesotérmico de verões brandos. A região sofre influência da continentalidade e da altitude em seu comportamento climático (AYOADE, 2001).
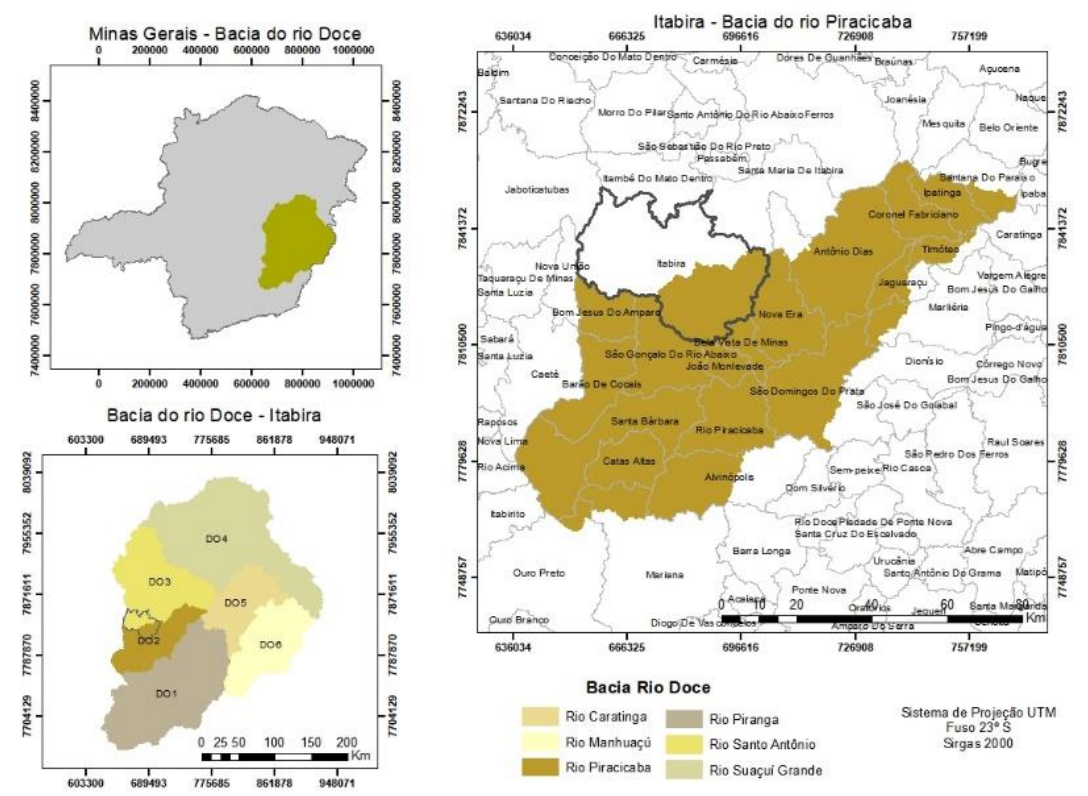

Figura 1 - Localização da bacia do rio Piracicaba em relação a Minas Gerais, bacia do rio Doce e o município de Itabira. 
Para a execução do estudo foi utilizado o SIG ArcGIS® versão 10.2.2. As escolhas das variáveis, informações e dados utilizados obedeceram a critérios de disponibilidade e qualidade da informação. Assim, as variáveis necessárias aos procedimentos de análises em ambiente SIG foram orientadas por pesquisas das melhores práticas em prospecção de potenciais hidroelétricos por estudos no Brasil em trabalhos de Ávila et al. (2003), Faria Filho (2007), Faria (2012) e Melo (2013).

\subsection{SELEÇÃO E PROCESSAMENTO DE DADOS}

Dada à falta de dados fluviométricos na bacia do rio Piracicaba, realizouse a regionalização das vazões médias para, posteriormente, com os resultados desta regionalização, determinar a vazão mínima Q_95 ajustada às características da bacia. As vazões Q95 e Q90 são as mais usadas como índices de vazão mínima na literatura (PYRCE, 2004; VESTENA et al., 2012).

Primeiramente foram selecionadas todas as estações fluviométricas disponíveis pertencentes à bacia do rio Piracicaba. As informações das estações foram obtidas por meio do Sistema de Informações Hidrológicas (HidroWeb) e do Sistema Nacional de Informações sobre Recursos Hídricos (SNIRH) da Agência Nacional de Águas (ANA).

Em seguida, foram pré-selecionadas todas as estações com dados consistidos disponíveis na área de estudo. Após o download destes dados, foi realizada a análise de consistência dos mesmos conforme Tucci (2002), sendo selecionadas as estações que apresentavam mais de cinco anos de série histórica. Ao existir falhas na série, é preferível não preenchê-las por regressão para evitar que sejam introduzidas tendenciosidades (TUCCI, 2002). Dessa forma, para definição das estações fluviométricas a serem utilizadas na regionalização de vazões, foi estipulado um limite de falhas de $10 \%$ para cada ano hidrológico das séries históricas de dados, sendo os anos com falhas superiores excluídos da análise.

\subsection{DETERMINAÇÃO DA CURVA DE PERMANÊNCIA}

Após o pré-processamento, foi calculada a curva de permanência para cada estação fluviométrica selecionada. A curva foi calculada pelo método da série completa de dados, na qual utiliza todos os anos disponíveis na série de dados, que, segundo Cruz (2001), possibilita a obtenção da curva de permanência, chamada de curva de permanência empírica total.

Para tal, ordenou-se a faixa total das vazões utilizadas na análise de forma decrescente, e em seguida, enumeraram-se todos os valores de acordo com sua ordem, a partir da vazão máxima. Posteriormente, os mesmos foram divididos pelo número total de valores existentes na amostra. O resultado foi transformado em porcentagem e lançado em um gráfico com os valores das vazões versus as contagens percentuais acumuladas correspondentes, traçandose a linha através dos pontos plotados. A partir da curva, foram obtidos os valores das vazões Q_95 para cada estação fluviométrica. 


\subsection{EXTRAÇÃO DAS VARIÁVEIS EXPLICATIVAS NO MODELO DE ELEVAÇÃO USANDO ARCGIS®}

Na metodologia para regionalização de vazões esquematizada por Tucci (2002), recomenda-se a utilização das seguintes características físicas:

> Área de drenagem $(A)$ : É a área plana inclusa entre os seus divisores topográficos e constitui-se o elemento básico para o cálculo das outras características físicas (CARVALHO; MELLO; SILVA, 2007). Portanto, é um dos parâmetros que tem mais peso na regressão.

$>$ Comprimento do rio principal $(L)$ : Define-se como o curso de água que drena a maior área no interior da bacia e, portanto, este parâmetro é utilizado como variável explicativa na regionalização de vazões (OLIVEIRA, 2013).

$>$ Declividade do rio principal (S): A declividade do rio principal de uma bacia é uma medida representativa do seu relevo muito utilizada em estudos hidrológicos. A velocidade do escoamento em um curso d'água natural depende da sua declividade, ou seja, quanto maior a declividade, maior a velocidade do escoamento (BAENA, 2002).

Por intermédio do software ArcGIS $®$ foi possível a determinação de todas as variáveis citadas acima. Para este estudo, optou-se por delimitar a bacia do rio Piracicaba ao invés de obtê-la pelo site da ANA, devido a constatações obtidas pelos trabalhos elaborados por Maciel et al.(2017) e Viera et al. (2017) ao realizarem a comparação entre os limites disponíveis e os gerados pelo software empregando modelos de elevação, uma vez que estes são muito próximos ao que é observado na realidade. Foram gerados os limites das microbracias a montante de cada estação e assim, os três parâmetros foram calculados para cada uma destas.

\subsection{IDENTIFICAÇÃO DAS REGIÕES HIDROLOGICAMENTE HOMOGÊNEAS E OBTENÇÃO DAS EQUAÇÕES REGIONAIS}

A verificação da homogeneidade da bacia foi definida em função da distribuição geográfica das estações e da combinação de estações que apresentou o melhor ajuste nos modelos de regressão, avaliado a partir de: valores do coeficiente de determinação $\left(R^{2}\right)$ maiores que 0,85 e valores do erro padrão fatorial $(\sigma F)$ menores que 1 (BAZZO, 2015). Quando os dois critérios apresentamm bons resultados, a região é definida como hidrologicamente homogênea para as vazões estudadas.

Para uma melhor avaliação da aplicação das variáveis na regressão, fezse uso dessas em combinações diferentes, variando de uma até três delas. A quantidade dessas foi limitada pelo fato da área de estudo apresentar dez estações fluviométricas destinadas à análise dos dados, as quais limita a utilização de mais variáveis, visto que a obtenção e a aplicação dos resultados de um estudo convencional de regionalização de vazões envolvem um processo mecânico e trabalhoso (BAENA, 2002). Para tanto, foi utilizado o software Excel.

Os coeficientes foram obtidos inserindo na planilha eletrônica construída no software Excel ${ }^{\circledR}$, os valores das variáveis independentes e dependentes, por meio de um sistema matricial elaborado, no qual a matriz $X$ representa as variáveis explicativas necessárias ao estudo, a matriz $\beta$, os coeficientes a serem determinados, e a matriz $Y$, o valor das vazões das estações. Após os passos citados anteriormente, procedeu-se os cálculos, obtendo-se as equações de 
vazões, com base nos modelos de regressão linear, potencial, exponencial, logarítmico e recíproco.

A análise das equações se deu em forma de testes, resultando em quinze o número total de simulações. Realizada a verificação da homogeneidade da região, fez-se a avaliação de desempenho dos modelos.

\subsection{CRITÉRIO DE DESEMPENHO DOS MODELOS DE REGRESSÃO}

Mesmo apresentando resultados estatísticos satisfatórios para $\mathrm{R}^{2}$ e $\sigma F$, tais modelos de regressão podem ter pouca representatividade física, com vazões estimadas apresentando anomalias como vazões negativas, ou ainda superestimativas maiores que o dobro das vazões observadas e subestimativas inferiores a sua metade.

Para verificar a adequação do ajuste da função matemática aos dados observados, existe uma série de avaliações objetivas que podem ser utilizadas. Dentre estas avaliações, as mais utilizadas são o cálculo do erro relativo (ER) entre o valor obtido a partir da série histórica $\left(Q_{o b s}\right)$ e o estimado $\left(Q_{\text {est }}\right)$ e o cálculo do coeficiente de Nash e Sutcliffe $\left(C_{N S}\right)$ (OLIVEIRA, 2013). Neste trabalho foram empregadas as duas avaliações.

Com os valores das vazões $Q_{95}$ obtidas a partir da curva de permanência das estações fluviométricas utilizadas no estudo, e das vazões estimadas com o MT, foi avaliada a precisão das metodologias por meio da aplicação do ER conforme Equação 1 e pelo $C_{N S}$, determinado pela Equação 2.

$$
\begin{gathered}
E R=100 \cdot\left(\frac{Q_{o b s}-Q_{e s t}}{Q_{o b s}}\right) \\
C_{N S}=\frac{\sum\left(Q_{o b s}-\overline{Q_{o b s}}\right)^{2}-\sum\left(Q_{o b s}-Q_{e s t}\right)^{2}}{\left(Q_{o b s}-\overline{Q_{o b s}}\right)^{2}}
\end{gathered}
$$

Em que:

$E R=$ erro relativo $(\%)$;

$Q_{o b s}=$ vazão obtida a partir da análise da série histórica do posto fluviométrico

$\left(\mathrm{m}^{3} / \mathrm{s}\right)$;

$\overline{Q_{o b s}}=$ vazão média obtida nos postos fluviométricos;

$Q_{e s t}=$ vazão estimada com base nas metodologias de regionalização $\left(\mathrm{m}^{3} / \mathrm{s}\right)$;

$C_{N S}=$ Coeficiente de Nash e Sutcliffe.

A estatística do coeficiente de Nash e Sutcliffe, que varia de 0 a 1 , compara a redução do desvio quadrático do erro do modelo com o desvio quadrático do modelo alternativo de prever sempre a média dos valores (SANTOS et al., 2015). Moriasi et al. (2007) apresentaram uma classificação para este coeficiente, sendo: $C_{N S}>0,65$ o modelo é considerado muito bom; $0,54<C_{N S}<0,65$ o modelo é considerado bom e; $0,5<C_{N S}<0,54$, satisfatório.

Valores negativos (-) do ER representam superestimativa das vazões, enquanto valores positivos $(+)$ representam vazões subestimadas pelos modelos. Considerou-se como a melhor metodologia de regionalização para cada bacia em estudo aquela que apresentou o menor erro relativo e o maior valor do coeficiente de eficiência de Nash e Sutcliffe. 


\section{RESULTADOS E DISCUSSÃO}

\subsection{SELEÇÃO DAS ESTAÇÕES FLUVIOMÉTRICAS DE MONITORAMENTO HIDROLÓGICO DA BACIA DO RIO PIRACICABA}

Foram identificadas no portal HidroWeb 63 estações fluviométricas na bacia do rio Piracicaba, entretanto somente 15 apresentaram dados de série histórica disponíveis.

Feita a triagem de dados, restaram 10 estações de monitoramento, trabalhando-se com as vazões médias diárias com diferentes intervalos amostrais de dados observados.

Diante do número disponível de estações, dez para uma área de $5.438,88 \mathrm{Km}^{2}$, executou-se a regionalização das vazões médias para a bacia, empregando vazões com permanência de $95 \%$ do tempo para as estações.

Essas dez estações fluviométricas foram utilizadas em conjunto para a regionalização de vazões média. A distribuição espacial das estações fluviométricas consideradas no estudo é apresentada na Figura 2.

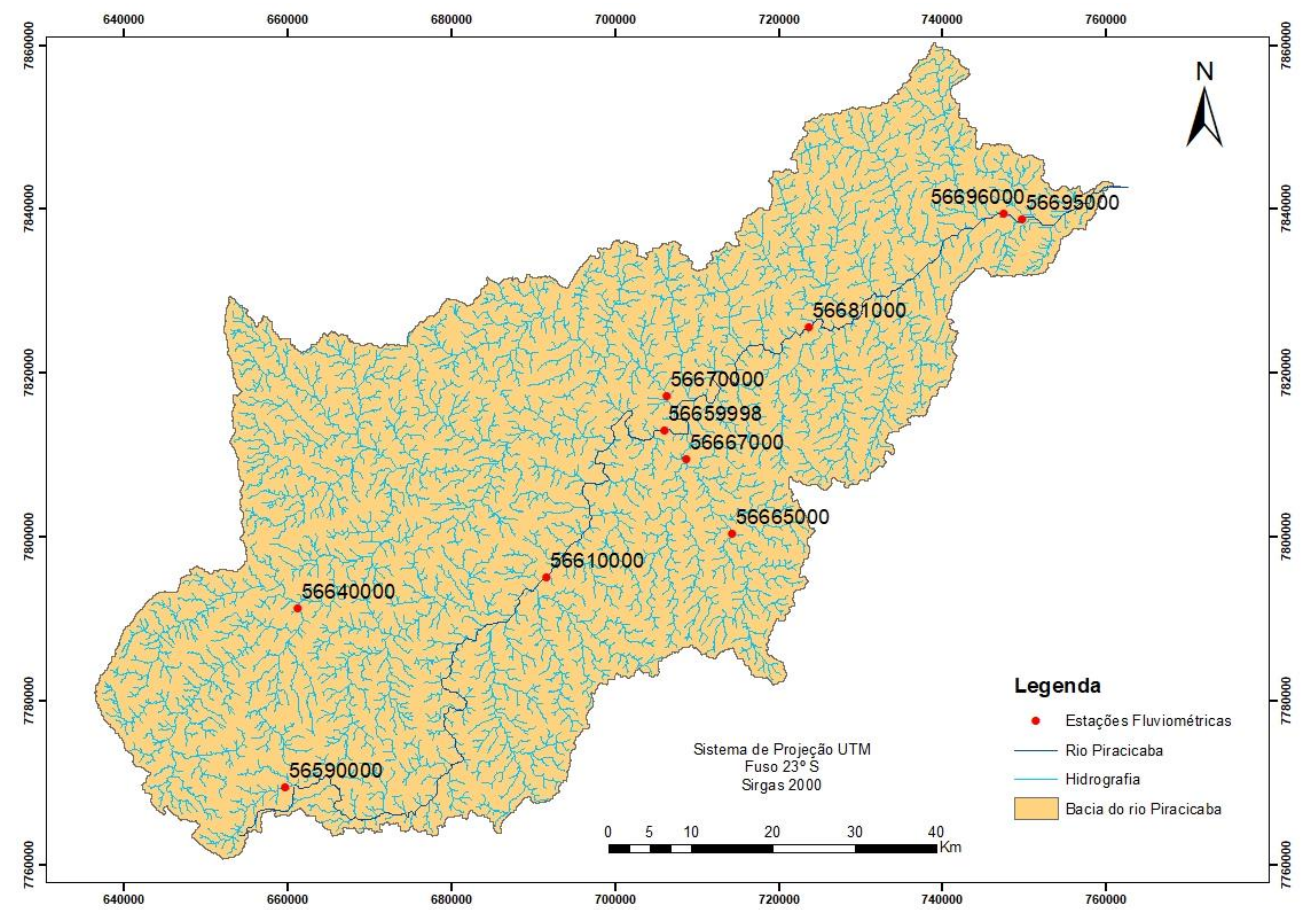

Figura 2 - Distribuição espacial das estações fluviométricas utilizadas na regionalização.

\subsection{OBTENÇÃO DAS VAZÕES DE PERMANÊNCIA Q_95}

De acordo com os procedimentos descritos, conforme recomendações de Tucci (2002), e seguindo o levantamento de dados obtidos, realizou-se a curva de permanência. A curva de permanência permite visualizar de imediato a potencialidade natural do rio, destacando a vazão mínima e o grau de permanência das diferentes magnitudes de vazão (EUCLYDES et al., 2001). 
Na Figura 3 são apresentadas as curvas de permanência de vazões das estações fluviométricas para a bacia hidrográfica do rio Piracicaba, totalizando 10 estações selecionadas no estudo.
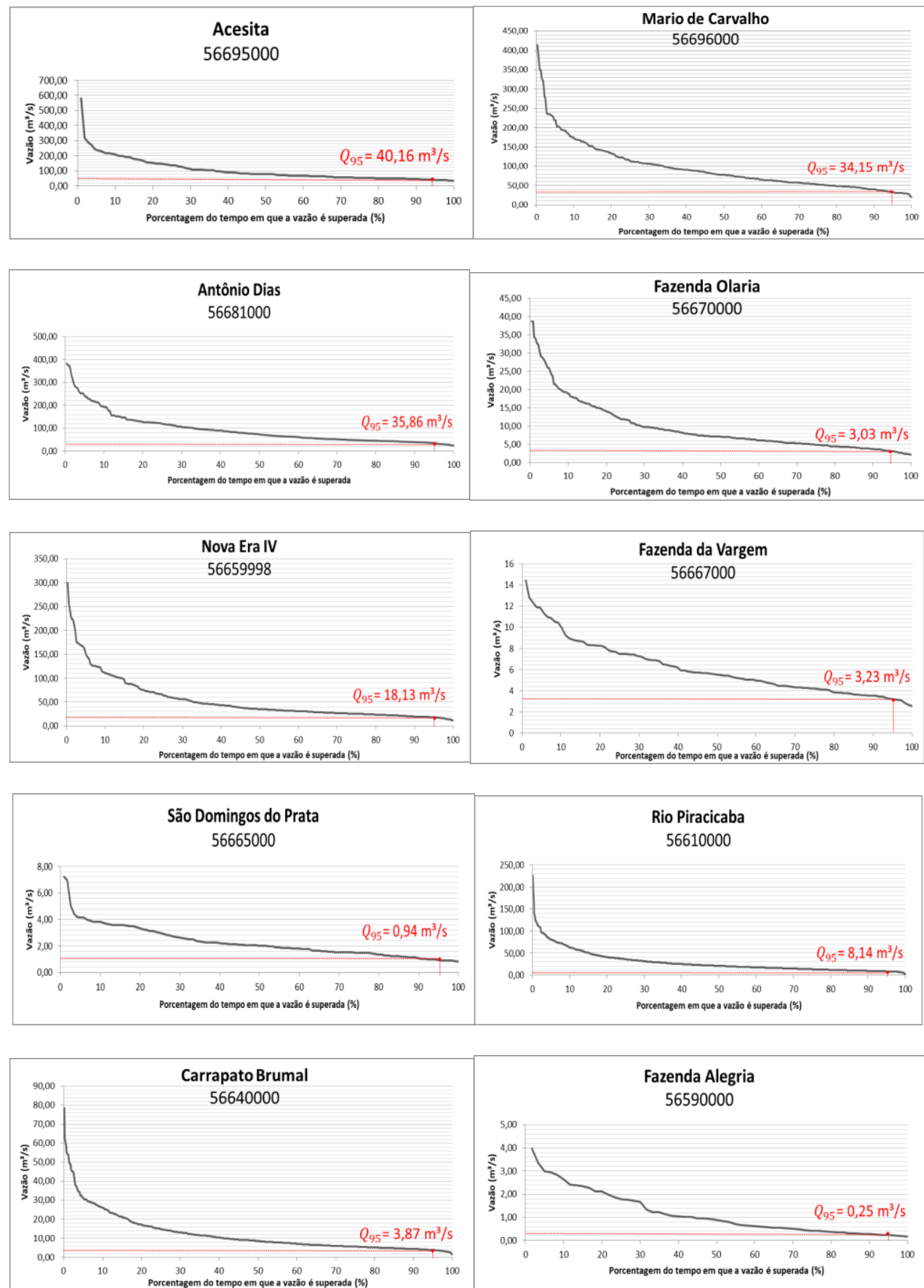

Figura 3 - Curva de permanência de vazões diárias das estações da bacia do rio Piracicaba selecionadas. 
Assim, os valores observados das vazões Q95 para as estações fluviométricas da bacia do rio Piracicaba estão resumidamente apresentados na Tabela 1.

Tabela 1 - Vazões $Q_{95}$ das estações fluviométricas

\begin{tabular}{ccc}
\hline Código & Estação & $Q_{95}\left(\mathrm{~m}^{3} / \mathrm{s}\right)$ \\
\hline 56695000 & Acesita & 40,16 \\
56696000 & Mario de Carvalho & 34,15 \\
56681000 & Antônio Dias & 35,86 \\
56670000 & Fazenda Olaria & 3,03 \\
56659998 & Nova Era IV & 18,13 \\
56667000 & Fazenda da Vargem & 3,23 \\
56665000 & São Domingos do Prata & 0,94 \\
56610000 & Rio Piracicaba & 8,14 \\
56640000 & Carrapato (Brumal) & 3,87 \\
56590000 & Fazenda Alegria & 0,25 \\
\hline
\end{tabular}

Analisando a Figura 3, é possível observar que os rios pertencentes à bacia do rio Piracicaba apresentam um comportamento típico, uma vez que a curva de permanência representa uma relação de regularidade das vazões diárias de uma bacia hidrográfica, ou seja, é capaz de indicar o comportamento com que a ocorrência das vazões aparece em um dado período de tempo.

Além disso, vale ressaltar que conforme esperado, os maiores valores de vazão $Q_{95}$ foram obtidos para as estações que estão localizadas no canal principal da bacia, ou seja, essas estações medem o escoamento superficial do rio Piracicaba, e as com menores valores localizadas nos afluentes. Assim, o valor da vazão $Q_{95}$ aumenta à medida que o ponto monitorado no rio se distancia da nascente deste rio e se aproxima de seu exutório. É o caso das estações de códigos 56695000, 56696000 e 56681000 (Figura 2), as quais apresentam os maiores valores da vazão $Q_{95}$ da bacia, visto que se encontram perto da foz da bacia do rio Piracicaba e, portanto, o valor da medição do local é o somatório das vazões contribuintes deste rio advindas de seus afluentes. Os menores valores da vazão são referentes ao monitoramento realizado próximo a nascente do rio Piracicaba ou em alguns de seus afluentes, como observada pelas estações 56590000 e 56640000 , respectivamente

Os valores encontrados da vazão se assemelham aos encontrados por Gasparini (2014), o qual avaliou a permanência das vazões na bacia hidrográfica do rio Itapemirim, localizada no Sul do estado do Espírito Santo. Além disso, Faria (2009) determinou a permanência das vazões na bacia do rio Miranda com dados hidrológicos de uma estação fluviométrica, pertencente na bacia do rio Paraguai, cuja área de drenagem é de $15.200 \mathrm{~km}^{2}$, obtendo um valor de 34,18 $\mathrm{m}^{3} / \mathrm{s}$. O resultado indica que para bacias com áreas superiores, as vazões médias apresentam boa correlação com a área de drenagem (SOUZA; SANTOS, 2013). 


\subsection{DETERMINAÇÃO DAS VARIÁVEIS PARA REGIONALIZAÇÃO}

A Tabela 2 apresenta as variáveis explicativas para as estações fluviométricas consideradas nesse estudo e a quantificação destas em cada ponto da estação, sendo A a área de drenagem, contabilizada em células que contribuem para o local da estação, L o comprimento do rio principal a montante do ponto e $\mathrm{S}$ a declividade deste rio.

Tabela 2 - Variáveis explicativas apropriadas para as estações da bacia do rio Piracicaba

\begin{tabular}{ccccr}
\hline Código & Estação & A (células) & \multicolumn{1}{c}{$\mathrm{L}(\mathrm{Km})$} & $\mathrm{S}(\mathrm{m} / \mathrm{Km})$ \\
\hline 56695000 & Acesita & 5939380 & 204,1853 & 6,45436722 \\
56696000 & Mario de Carvalho & 5891910 & 200,6336 & 6,577530053 \\
56681000 & Antônio Dias & 4756790 & 166,5957 & 7,038250588 \\
56670000 & Fazenda Olaria & 446271 & 45,33953 & 10,14586122 \\
56659998 & Nova Era IV & 3425920 & 128,7896 & 8,027002279 \\
56667000 & Fazenda da Vargem & 312492 & 37,68037 & 7,299262486 \\
56665000 & São Domingos do Prata & 155086 & 24,21935 & 9,772405397 \\
56610000 & Rio Piracicaba & 1302550 & 88,71579 & 10,4827491 \\
56640000 & Carrapato (Brumal) & 472029 & 44,1725 & 16,75321112 \\
56590000 & Fazenda Alegria & 63199 & 17,55299 & 36,76925652 \\
\hline
\end{tabular}

Os resultados apresentados na Tabela 2, para a variável área de drenagem, neste estudo empregando o fluxo acumulado, são semelhantes aos apresentados por Carvalho Junior et al. (2008), em estudo de identificação de áreas potenciais para implantação de pequenas centrais hidrelétricas na bacia do rio Preto, presente no Distrito Federal e nos estados de Goiás e Minas Gerais. Com o propósito de obter a vazão ao longo de todo o canal, o autor realizou a regionalização da vazão utilizando como base o mapa de área de contribuição.

Outros parâmetros poderiam também ser empregados, contudo, o mais representativo tem sido a área de drenagem, como observado por Castiglioni (2013), que testou equações de regionalização com até seis variáveis explicativas, dentre eles área de drenagem, comprimento do rio principal, densidade de drenagem, perímetro, altitude e precipitação média, e foi encontrado de forma geral, que a área de drenagem gerou resultados satisfatórios para a regionalização da curva de probabilidade de vazões mínimas, podendo ser utilizada como única variável explicativa para a estimativa das vazões de referência no seu estudo. Contudo, neste trabalho, testou-se as três varáveis.

\subsection{IDENTIFICAÇÃO DA REGIÃO HIDROLOGICAMENTE HOMOGÊNEA}

Foram analisados os melhores ajustes estatísticos das seguintes combinações de variáveis: área de drenagem; área de drenagem e comprimento do rio principal; área de drenagem, comprimento do rio principal e declividade do rio principal. A Tabela 3 apresenta as equações obtidas em todas as tentativas de regionalização realizadas para a vazão média, bem como $\mathrm{R}^{2}$ e $\sigma F$ associados ao conjunto das estações fluviométricas consideradas neste estudo. 
Para as tentativas de regionalização que envolveram análises de regressão múltipla, o coeficiente de correlação apresentado é o ajustado $\left(R^{2} a\right)$ que, segundo Levine et al. (2005), é o coeficiente mais indicado para esse tipo de análise por refletir o número de variáveis explicativas e o tamanho da amostra.

Tabela 3 - Equações de regionalização pelo Método Tradicional (Q95)

\begin{tabular}{|c|c|c|c|c|c|}
\hline $\begin{array}{l}\text { Variável } \\
\text { Explicativa }\end{array}$ & Modelo & $\mathbf{R}^{\mathbf{2}}$ & $\begin{array}{c}\text { Erro } \\
\text { Padrão } \\
(\sigma F)\end{array}$ & Equação de Regionalização & \\
\hline \multirow{5}{*}{$A$} & Linear & 1,0000 & $3,5743^{-15}$ & $Q_{95}=0,18716+6,4083 \cdot 10^{-6} \cdot A$ & [1] \\
\hline & Potencial & 0,99996 & 0,1156 & $Q_{95}=4,64075 \cdot 10^{-6} \cdot A^{1,02453}$ & [2] \\
\hline & Exponencial & 0,89238 & 7,4594 & $\mathrm{Q}_{95}=e^{\left(0,43159+6,0037 \cdot 10^{-7} * \mathrm{~A}\right)}$ & [3] \\
\hline & Logarítmico & 0,83749 & 6,1694 & $Q_{95}=-106,77+8,8447 \cdot \ln A$ & [4] \\
\hline & Recíproco & 0,57024 & 0,0454 & $\mathrm{Q}_{95}=\left(0,015239+1,1530 \cdot 10^{-7} \cdot A\right)^{-1}$ & [5] \\
\hline \multirow{5}{*}{$A$ e $L$} & Linear & 1,0000 & $3,0395^{-15}$ & $\begin{array}{l}Q_{95}=0,27208+6,4968 \cdot 10^{-6} \cdot A- \\
0,0029894 . L\end{array}$ & [6] \\
\hline & Potencial & 0,9899 & 1,8305 & $\mathrm{Q}_{95}=4,3183 \cdot 10^{-8} \cdot A^{1,8010} \cdot L^{-1,4147}$ & [7] \\
\hline & Exponencial & 0,86641 & 8,1146 & $\mathrm{Q}_{95}=e^{-1,4996-1,4118 \cdot 10^{-6} * \mathrm{~A}+0,067985 * \mathrm{~L}}$ & [8] \\
\hline & Logarítmico & 0,99413 & 1,2892 & $\begin{array}{l}Q_{95}=60,565-18,934 . \ln A+ \\
50,611 . \ln \mathrm{L}\end{array}$ & [9] \\
\hline & Recíproco & 0,85576 & 0,17054 & $\begin{array}{l}\mathrm{Q}_{95}=\left(0,0033691-8,7249 \cdot 10^{-7} \cdot A+\right. \\
0,029843 \cdot L)^{-1}\end{array}$ & [10] \\
\hline \multirow{5}{*}{$A, L$ e $S$} & Linear & 1,0000 & $5,2652^{-15}$ & $\begin{array}{l}Q_{95}=0,98687+6,7986 \cdot 10^{-6} \cdot A- \\
0,015132 \cdot L-0,0094447 . S\end{array}$ & [11] \\
\hline & Potencial & 0,97002 & 9,4543 & $\begin{array}{l}\mathrm{Q}_{95}=0,000030771 \cdot A^{1,3617} \\
L^{-1,1195} \cdot S^{-0,60794}\end{array}$ & [12] \\
\hline & Exponencial & 0,90384 & 5,5282 & $\begin{array}{l}\mathrm{Q}_{95}= \\
e^{0,75733-4,58756.10^{-7} * \mathrm{~A}+0,029645 * \mathrm{~L}-0,029822 . \mathrm{S}}\end{array}$ & [13] \\
\hline & Logarítmico & 0,99144 & 1,3345 & $\begin{array}{l}Q_{95}=73,306-19,786 . \ln A+ \\
51,184 . \ln L-1,1792 . \ln S\end{array}$ & [14] \\
\hline & Recíproco & 0,87978 & 0,10244 & $\begin{array}{l}\mathrm{Q}_{95}=\left(0,0037786-5,7858 \cdot 10^{-7} \cdot A+\right. \\
0,020946 \cdot L+0,0091294 \cdot S)^{-1}\end{array}$ & [15] \\
\hline
\end{tabular}

Conforme Tabela 3, a análise de verificação realizada para a região constatou, além dos $\mathrm{R}^{2}$, os valores de $\sigma \mathrm{F}$ obtidos com os modelos matemáticos utilizados, tendo alguns resultados considerados insatisfatórios para uma $\mathrm{RHH}$. Os valores de $R^{2}$ das equações de regionalização variaram de 0,75514 a 1,0, indicando inadequação de alguns modelos à representação da vazão de permanência em $95 \%$ do tempo. Obtiveram-se também valores de erros padrões maiores do que 1 , variando de 5,2652-15 a 9,4543, fazendo com que, num total de 15 modelos de regressão, 9 não fossem enquadrados na $\mathrm{RHH}$.

Entretanto, pelo fato de apenas em dois casos (Equações 4 e 5) os valores $R^{2}$ obtidos terem sido inferiores a 0,85 (com valores 0,83749 e 0,57024, respectivamente), não houve a necessidade de subdividir as estações dentro da bacia em mais regiões, visto que todos os modelos de regressão apresentaram 
coeficientes de determinação maiores que 0,5 , que, segundo Collischonn (2001), para que se obtenha bons resultados na regionalização, um índice de desempenho entre 0,36 a 0,75, estabelece uma resposta das funções regionais na faixa de desempenho de aceitável, e é considerado adequado e bom se o valor de $\mathrm{R}^{2}$ supera 0,75 .

Pereira (2012), ao regionalizar as vazões de permanência pelo MT para a região hidrográfica do Uruguai, encontrou of com valores que variaram de 0,08 a 48,35 e $\mathrm{R}^{2}$ de 0,15 a 0,98 para a $\mathrm{RHH} 1$, subdivisão considerada adequada pelo autor para a definição das regiões com comportamento hidrológico semelhante. Assim, os valores obtidos no presente estudo estão em concordância e/ou são mais adequados que os encontrados pelo autor.

Desse modo, as melhores equações selecionadas para estimar as vazões Q_95 pelo MT, na bacia do rio Piracicaba, foram todas as equações do modelo Linear (Equações 1, 6 e 11), o modelo Potencial utilizando a variável explicativa A (Equação 2), e o modelo Recíproco utilizando como variáveis explicativas combinadas A e L (Equação 10) e A, L e S (Equação 15). Analisando-se os modelos selecionados, verifica-se que a área de drenagem foi a variável que se mostrou suficiente para a estimativa da Q_95, embora a incorporação das demais variáveis nos modelos de regressão também tenha se mostrado satisfatória.

\subsection{ANÁLISES ESTATÍSTICAS E ESCOLHA DO MODELO DE REGRESSÃO PARA A REGIONALIZAÇÃO DE VAZÕES}

De posse das equações recomendadas, obtiveram-se os valores das vazões estimadas para cada uma destas equações e, então, estes foram comparados aos valores das vazões observadas para a bacia. Na Tabela 4 estão apresentados os erros relativos percentuais, os valores dos coeficientes de eficiência de Nash e Sutcliffe e os valores da $Q_{95}$ observados e estimados para 0 MT.

A fim de visualizar melhor a representatividade do ER, a Figura 4 apresenta as $Q_{95}$ reais e estimadas das estações e seus respectivos erros percentuais. Para fins de análise, os erros relativos percentuais negativos nesta tabela correspondem a superestimativa das vazões estimadas, enquanto os positivos, às subestimativas. 
Tabela 4 - Vazões Q95 reais e estimadas, erro percentual e coeficiente de eficiência de Nash e Sutcliffe - Resultados associados à função regional de regressão das equações selecionadas

\begin{tabular}{|c|c|c|c|c|c|c|c|c|c|c|c|c|c|c|c|c|c|c|}
\hline \multirow{4}{*}{ Estação } & \multicolumn{9}{|c|}{ Linear } & \multirow{2}{*}{\multicolumn{3}{|c|}{$\frac{\text { Potencial }}{\mathrm{A}}$}} & \multicolumn{6}{|c|}{ Recíproca } \\
\hline & \multicolumn{3}{|c|}{$A$} & \multicolumn{3}{|c|}{$A$ e $L$} & \multicolumn{3}{|c|}{$A$, Le $S$} & & & & \multicolumn{3}{|c|}{$A$ e $L$} & \multicolumn{3}{|c|}{ A, Le $S$} \\
\hline & $\begin{array}{c}\text { Q950 } \\
\text { bs }\end{array}$ & Q95est & $\begin{array}{c}\text { Erro } \\
\text { Relativo } \\
\end{array}$ & $\begin{array}{c}\text { Q95o } \\
\text { bs }\end{array}$ & Q95est & $\begin{array}{c}\text { Erro } \\
\text { Relativo }\end{array}$ & $\begin{array}{c}\text { Q950 } \\
\text { bs }\end{array}$ & Q95est & $\begin{array}{c}\text { Erro } \\
\text { Relativo }\end{array}$ & $\begin{array}{c}\text { Q950 } \\
\text { bs }\end{array}$ & Q95est & $\begin{array}{c}\text { Erro } \\
\text { Relativo }\end{array}$ & $\begin{array}{c}\text { Q950 } \\
\text { bs }\end{array}$ & Q95est & $\begin{array}{c}\text { Erro } \\
\text { Relativo } \\
\end{array}$ & $\begin{array}{c}\text { Q95ob } \\
\mathrm{s}\end{array}$ & Q95est & $\begin{array}{c}\text { Erro } \\
\text { Relativo } \\
\end{array}$ \\
\hline & $\left(\mathrm{m}^{3} / \mathrm{s}\right)$ & $\left(\mathrm{m}^{3} / \mathrm{s}\right)$ & ER\% & $\left(\mathrm{m}^{3} / \mathrm{s}\right)$ & $\left(\mathrm{m}^{3} / \mathrm{s}\right)$ & ER\% & $\left(\mathrm{m}^{3} / \mathrm{s}\right)$ & $\left(\mathrm{m}^{3} / \mathrm{s}\right)$ & ER\% & $\left(\mathrm{m}^{3} / \mathrm{s}\right)$ & $\left(\mathrm{m}^{3} / \mathrm{s}\right)$ & ER\% & $\left(\mathrm{m}^{3} / \mathrm{s}\right)$ & $\left(\mathrm{m}^{3} / \mathrm{s}\right)$ & ER\% & $\left(\mathrm{m}^{3} / \mathrm{s}\right)$ & $\left(\mathrm{m}^{3} / \mathrm{s}\right)$ & ER\% \\
\hline 56695000 & 40,16 & 38,2483 & 4,7601 & 40,16 & 38,24838 & 4,7600 & 40,16 & 38,21569 & 4,8414 & 40,16 & 40,082 & 0,19526 & 40,16 & 1,09318 & 97,278 & 40,16 & 1,1071 & 97,243 \\
\hline 56696000 & 34,15 & 37,9441 & $-11,110$ & 34,15 & 37,9506 & $-11,129$ & 34,15 & 37,94554 & $-11,114$ & 34,15 & 40,077 & $-17,357$ & 34,15 & 1,17621 & 96,556 & 34,15 & 1,1662 & 96,585 \\
\hline 56681000 & 35,86 & 30,6699 & 14,473 & 35,86 & 30,67776 & 14,451 & 35,86 & 30,73902 & 14,280 & 35,86 & 32,187 & 10,243 & 35,86 & 1,21244 & 96,619 & 35,86 & 1,2415 & 96,538 \\
\hline 56670000 & 3,03 & 3,04698 & $-0,5606$ & 3,03 & 3,035855 & $-0,1932$ & 3,03 & 3,238998 & $-6,8976$ & 3,03 & 2,849 & 5,9601 & 3,03 & 1,03406 & 65,872 & 3,03 & 1,2692 & 58,113 \\
\hline 56659998 & 18,13 & 22,1414 & $-22,126$ & 18,13 & 22,14444 & $-22,143$ & 18,13 & 22,2537 & $-22,745$ & 18,13 & 22,996 & $-26,837$ & 18,13 & 1,16588 & 93,569 & 18,13 & 1,2617 & 93,041 \\
\hline 56667000 & 3,23 & 2,18969 & 32,208 & 3,23 & 2,189622 & 32,210 & 3,23 & 2,47227 & 23,459 & 3,23 & 1,978 & 38,765 & 3,23 & 1,16930 & 63,799 & 3,23 & 1,4730 & 54,396 \\
\hline 56665000 & 0,94 & 1,18099 & $-25,638$ & 0,94 & 1,207235 & $-28,429$ & 0,94 & 1,582461 & $-68,347$ & 0,94 & 0,965 & $-2,6461$ & 0,94 & 1,69253 & $-80,057$ & 0,94 & 1,9586 & $-108,36$ \\
\hline 56610000 & 8,14 & 8,53425 & $-4,8435$ & 8,14 & 8,46922 & $-4,0445$ & 8,14 & 8,400953 & $-3,2058$ & 8,14 & 8,538 & $-4,8904$ & 8,14 & 0,66031 & 91,888 & 8,14 & 0,8305 & 89,798 \\
\hline 56640000 & 3,87 & $\begin{array}{c}3,21205 \\
2\end{array}$ & 17,0012 & 3,87 & 3,206688 & 17,140 & 3,87 & 3,369371 & 12,936 & 3,87 & 3,018 & 22,015 & 3,87 & 1,09919 & 71,597 & 3,87 & 1,2363 & 68,055 \\
\hline 56590000 & 0,25 & 0,59215 & $-136,86$ & 0,25 & 0,630196 & $-152,08$ & 0,25 & 0,803655 & $-221,46$ & 0,25 & 0,385 & $-53,853$ & 0,25 & 2,11838 & $-747,355$ & 0,25 & 1,4913 & $-496,51$ \\
\hline ER Médio & & & $-13,270$ & & & $-14,946$ & & & $-27,825$ & & & $-2,8404$ & & & $-15,023$ & & & 4,8898 \\
\hline CNS & & & 0,97279 & & & 0,97279 & & & 0,97272 & & & 0,96765 & & & $-0,80679$ & & & $-0,80140$ \\
\hline
\end{tabular}


Revista Brasileira de Climatologia

ISSN: 2237-8642 (Eletrônica)

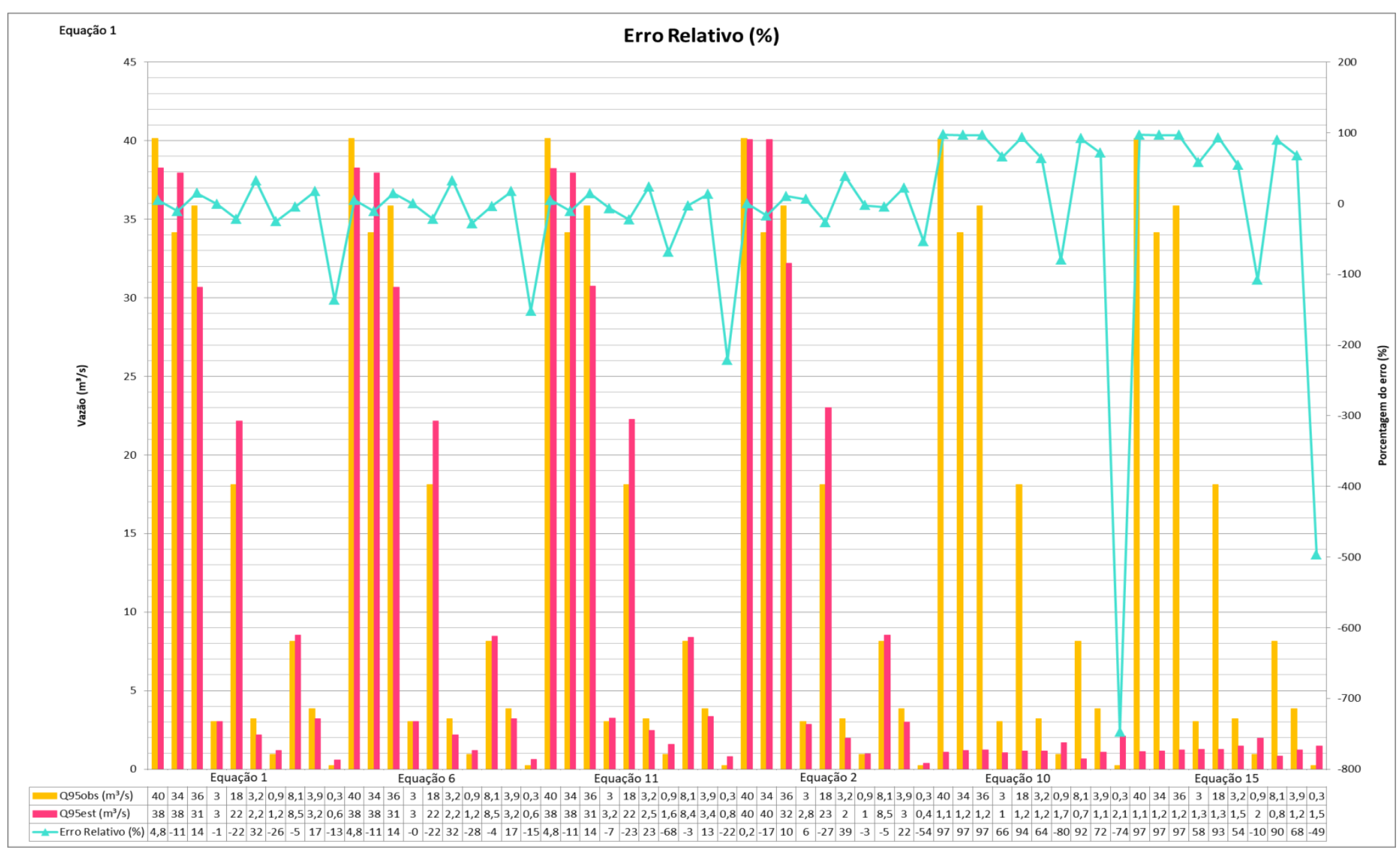

Figura 4 - Comparação entre as $Q_{95}$ reais e estimadas das estações e seus respectivos erros percentuais 
Na análise das equações de regressão selecionadas para a regionalização da $Q_{95}$ apresentada na Tabela 4, pode-se observar que os coeficientes de eficiência de Nash e Sutcliffe obtidos foram considerados muito bom para os modelos linear e potencial. Entretanto, para o modelo recíproco em ambas as equações 10 e 15, os valores encontrados foram negativos. Portanto, este modelo foi descartado para a escolha da equação de melhor desempenho de regionalização para a bacia do rio Piracicaba, como pode ser comprovado visivelmente pela Figura 4.

Observando-se os resultados apresentados na Tabela 4 e analisando-se a Figura 4, verifica-se que o MT de regionalização de vazões aplicado para a estima da $Q_{95}$ apresentou erro relativo médio variando de $-27,825 \%$ a $4,8898 \%$. Estudo realizado por Fioreze, Oliveira e Franco (2008), ao avaliar o desempenho de equações de regionalização de vazões $Q_{95}$ ajustadas por Cortês (2004) e Proni (BRASIl, 1987) nas bacias hidrográficas do Ribeirão Santa Bárbara-GO, utilizando o método Tradicional, encontrou erros relativos bastante altos, variando de $-24,33 \%$ a $144,80 \%$, o qual evidencia algumas limitações na utilização do MT. Entretanto, Segundo Lemos (2006), este método é ainda um dos mais utilizados em estudos de regionalização e o que tem apresentado sistematicamente os resultados mais satisfatórios, apresentando menores erros relativos médios quando em comparação com outras metodologias.

Embora os erros relativos encontrados para as estações fluviométricas apresentem valores altos, tem-se que o MT tende a representar de forma fidedigna as vazões observadas, demonstrando que os modelos de regressão restantes (Equações 1, 2, 6 e 11) apresentam qualidade para representar esta bacia hidrográfica devido aos altos valores do coeficiente de Nash e Sutcliffe encontrados, os quais variaram entre 0,96765 a 0,97279.

Os resultados encontrados no presente estudo corroboram com outras pesquisas realizadas na área, como a de Azevedo (2004), que avaliou as metodologias: tradicional, descrita pela Eletrobrás (1985); de Chaves et al. (2002); e baseada na interpolação linear para a regionalização de vazões mínimas de referência $\left(Q_{7,10}, Q_{90}\right.$ e $\left.Q_{95}\right)$ para a sub-bacia do rio Paraná, verificando que a melhor metodologia de regionalização foi a tradicional, baseada na utilização de equações de regressão regionais, com erro relativo médio de 13,58\% e coeficiente de eficiência de Nash e Sutcliffe médio de 0,97.

Levando em conta os valores da performance estatística da estimativa do desempenho, a equação 2 de modelo potencial apresentou-se como a mais adequada para a obtenção das vazões da $Q_{95}$, em relação ao número de estações fluviométricas avaliadas, uma vez que apresentou menores valores de erro relativo.

De posse da imagem SRTM e da rede de drenagem gerada pelo processamento hidrológico, foi gerado, empregando a álgebra de mapas, por meio da ferramenta Calculadora de Raster do ArcGIS, o mapa da $Q_{95}$ foi gerado para a área de estudo, tendo como entrada o mapa de fluxo acumulado na equação $Q_{95}=4,64075 \cdot 10^{-6} \cdot A^{1,02453}$, definida na regionalização da bacia, conforme Figura 5. Neste caso, os valores foram obtidos pixel a pixel, correspondendo ao valor da vazão atribuída em cada pixel dos rios presentes na bacia, como apresentado na Figura 5. Assim a $Q_{95}$ foi obtida para todos os rios de forma espacializada, sem, contudo, acarretar em ganho adicional de tempo por empregar um sistema de informação geográfico. 


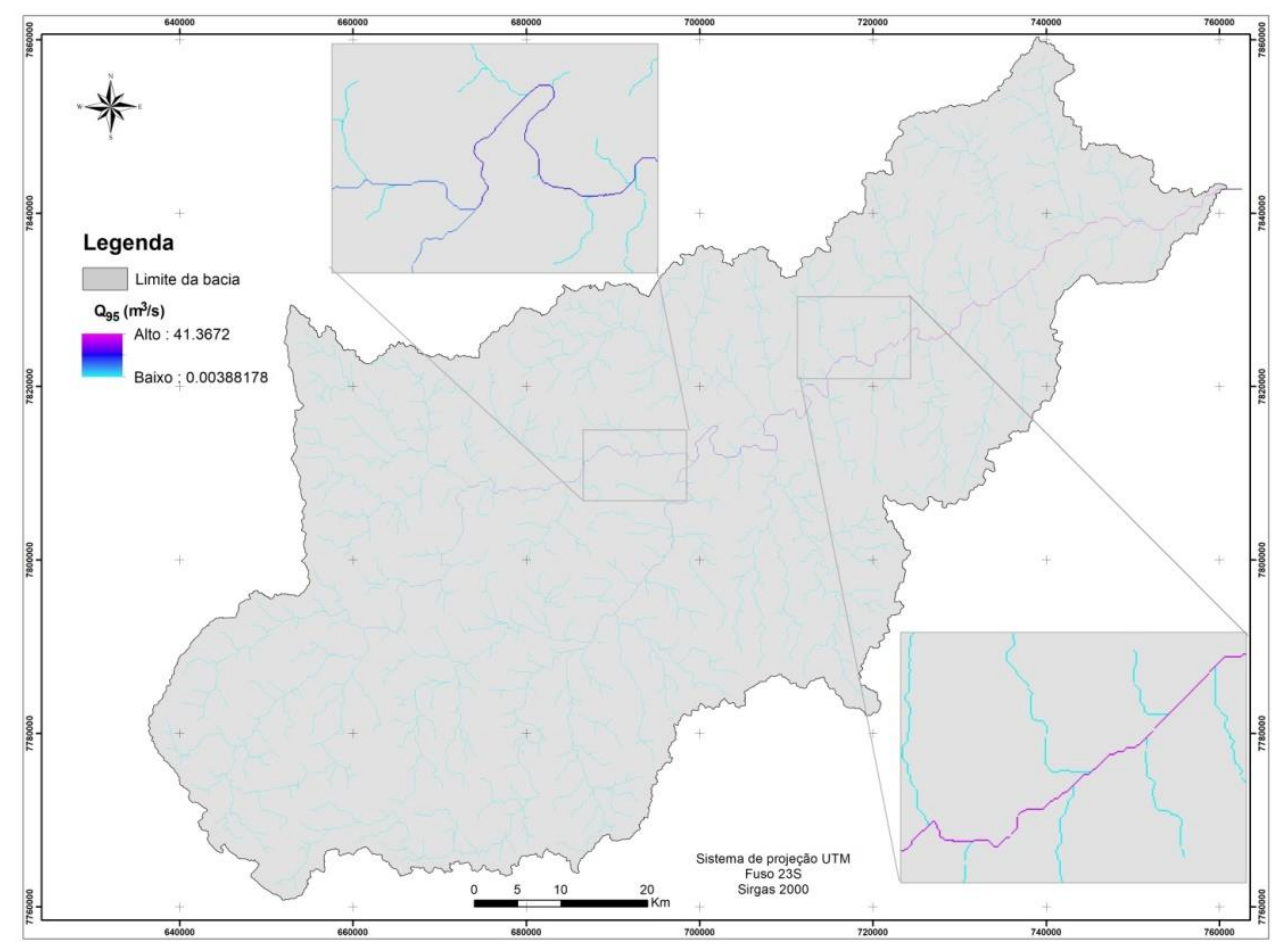

Figura 5 - Mapa da Q95.

Por tudo isso, pode-se inferir que o modelo potencial apresentou excelentes resultados, com erros menores do que em relação aos outros modelos, sendo, portanto, passível de aplicação.

O emprego da equação de regionalização na ferramenta Calculadora de Raster, tendo como parâmetro de entrada o mapa de fluxo acumulado, se mostra replicável para outras bacias visto que a base de dados empregadas é de acesso livre e disponível para todo o globo terrestre.

\section{CONCLUSÕES}

A escassez de dados hidrológicos disponíveis das estações meteorológicas na bacia em estudo foi suprida pela regionalização de vazões, no intuito de obter a informação hidrológica em locais sem medição. Assim, este estudo possibilitou a regionalização da vazão Q95 para todos os rios da bacia em nível de célula. Contudo, deve-se ressaltar que este não substitui uma densa rede hidrometeorológica.

A área de drenagem caracterizou-se como a variável mais expressiva para a representação da vazão $Q_{95}$ para toda a bacia, considerada como uma região hidrologicamente homogênea.

Pelo Método Tradicional, o modelo potencial apresentou-se como o mais adequado para a regionalização de vazões, com $C_{N S}$ classificado como muito bom.

Embora a metodologia empregada não substitua uma densa rede hidrometeorológica, esta apresentou resultado satisfatório na medida que permitiu a obtenção da Q95 de forma espacializada para os principais rios da bacia, inovando ao que tradicionalmente se faz, que seria por área. 
A disponibilidade de dados é crucial para a análise de eventos extremos e o gerenciamento de risco em uma região. Por isso, a regionalização de vazões, levando-se em conta suas limitações, tem grande importância para o planejamento e gestão dos recursos hídricos, além de fornecer subsídios para o estudo do impacto das alterações climáticas e as mudanças associadas na disponibilidade de água.

O emprego da equação de regionalização, tendo como parâmetro de entrada o mapa de fluxo acumulado a partir dos dados do SRTM, que pode ser gerado para qualquer bacia e mesmo empregando sistemas não comerciais como SPRING, QGIS, SAGA GIS, TerraView, entre outros, pois são ferramentas presentes nestes, permite a replicação desta metodologia para regiões com escassez de dados hidrológicos. Neste contexto esta metodologia proporcionaria maior agilidade nas tomadas de decisões em comitês gestores, por exemplo, visto que aceleraria a obtenção da vazão em um ponto de solicitação de outorga.

\section{REFERÊNCIAS BIBLIOGRÁFICAS}

A'B SABER A.N. Os domínios de natureza no Brasil: potencialidades paisagísticas. São Paulo, Ateliê Editorial, 2003.

ANDRADE, E. M.; HAWKINS, R. H. Aplicação da função de Andrews na avaliação da regionalização de bacias em regiões áridas e semi-áridas. Revista Brasileira de Recursos Hídricos, Porto Alegre, v. 5, n. 4, p. 17-24, 2000.

ÁVILA, C. J. C.P et al. Uso de ferramentas de SIG para inventário preliminar de potenciais remanescentes. In Encontro de Energia no Meio Rural, n. 4, 2003, Campinas. Anais... Campinas, v. 5, n. 17, p. 24-28. 2003.

AYOADE, J.O. Introdução a climatologia para os trópicos. Tradução: Maria Juraci Zani dos Santos. Rio de Janeiro: Bertrand, 2001.

AZEVEDO, A. A. Avaliação de metodologia de regionalização de vazões mínimas de referência para a sub-bacia do rio Paranã. Viçosa, MG, 2004. 108 f. Dissertação (Mestrado em Engenharia Agrícola) - Universidade Federal de Viçosa, Viçosa, 2004.

BAENA, L.G.N. Regionalização de vazões para a bacia do rio Paraíba do Sul, a montante de Volta Redonda, a partir de modelo digital de elevação hidrologicamente consistente. 2002. 135 f. Tese (Mestre em Recursos Hídricos e Ambientais) - Universidade Federal de Viçosa, Viçosa - MG, 2002.

BAZZO, K. R. Regionalização de vazões de permanência para bacias hidrográficas do estado do Rio Grande do Sul. 2015. 63 p. Trabalho de Conclusão de Curso (Bacharel) - Engenharia Ambiental e Sanitária, Centro de Engenharias da Universidade Federal de Pelotas, Pelotas, 2015.

BRASIL. Ministério da Integração Social. Programa Nacional de Irrigação PRONI. Disponibilidade Hídrica. Região do Rio dos Bois. Regionalização. Mapas. Brasília: Ministério da Irrigação, 1987.

CARVALHO JUNIOR, O. A. et al. Metodologia para identificação de áreas potenciais para implantação de pequenas centrais hidrelétricas na bacia do rio Preto utilizando sistema de Informações Geográficas. Revista Brasileira de Cartografia, n. 60/02, p.195-203, agosto 2008. ISSN 1808-0936. 
CARVALHO, D. F.; MELLO, J. L. P.; SILVA, D.B. Hidrologia. 2007. Universidade Federal do Rio de Janeiro, Departamento de Engenharia.

CASTIGLIONI, I. F. Análise regional de vazões para a bacia hidrográfica do rio Itapemirim. 2013. 170 f. Trabalho de Conclusão de curso (Bacharel) Engenharia Ambiental, Universidade Federal do Espírito Santo, Vitória, 2013.

CATELANI, C. S. Geotecnologias aplicadas á análise do assoreamento de reservatórios de hidrelétricas em cenário de escassez de dados de séries históricas. 2015. 140 p. Tese (Doutorado em Engenharia Mecânica em área de Energia) - Universidade Estadual Paulista, Guaratinguetá, 2015.

CHAVES, H. M. L. et al. Regionalização de vazões mínimas em bacias através de interpolação em sistemas de informação geográfica. Revista Brasileira de Recursos Hídricos, v. 7, n. 3, p. 43-51, 2002.

COLLISCHONN, W. Simulação hidrológica em grandes bacias. 2001. 194 f. Tese (Doutorado em Recursos Hídricos e Engenharia Ambiental) - Universidade Federal do Rio Grande do Sul, Porto Alegre: UFRGS, 2001.

CORTÊS, F. C. Obtenção e validação de modelos de regionalização de vazão na bacia do Rio dos Bois, Estado de Goiás, 2004. Dissertação (Mestrado em Ciências Agrárias) - Faculdade de Agronomia e Medicina Veterinária da Universidade de Brasília, Brasília, 2004.

CRUZ, J. C. Disponibilidade Hídrica para outorga: avaliação de aspectos técnicos e conceituais. 2001. 199 p. Tese para obtenção do título de Doutor em Engenharia, Universidade Federal do Rio Grande do Sul, Porto Alegre, RS, 2001.

ELETROBRAS - Centrais Elétricas Brasileiras S.A. Metodologia para Regionalização de Vazões. Rio de Janeiro, 1985. v. 2.

EUCLYDES, H. P. et al. Regionalização hidrológica na bacia do Alto São Francisco a montante da barragem de Três Marias, MG. Revista Brasileira de Recursos Hídricos, Porto Alegre, v.6, n.2, p.81-105, 2001.

FARIA FILHO, R. F. F. Avaliação do potencial hidráulico em bacias hidrográficas por meio de sistemas de informações geográficas. 2007. 72 f. Dissertação (Mestrado em Engenharia Agrícola) - Universidade Federal de Viçosa, Viçosa, 2007.

FARIA, B. P. Avaliação da disponibilidade hídrica para concessão de outorgas baseada em vazões de referência. 2009. 27 f. Trabalho de Conclusão de Curso (Bacharel)- Engenharia Ambiental, Centro de Ciências Exatas e Tecnologia da Universidade Federal de Mato Grosso do Sul, Campo Grande, MS, 2009.

FARIA, E. J. R. I. Regionalização de potencial hidrelétrico com escassez de dados: aplicação Moçambique. 2012. 194 p. Dissertação (Mestrado em Engenharia de Recursos Hídricos e Saneamento Ambiental) - Instituto de Pesquisas Hidráulicas da Universidade Federal do Rio Grande do Sul, Porto Alegre, 2012.

FIOREZE, A.P.; OLIVEIRA, L. F.; FRANCO, A. P. B. Avaliação do desempenho de equações de regionalização de vazões na bacia hidrográfica do Ribeirão Santa Bárbara, Goiás, Brasil. Ambi-Agua, Taubaté, v.3, n.2, p. 62-76, 2008.

GASPARINI, K. A. C. Regionalização de vazões para a bacia hidrográfica do rio Itapemirim, ES. 2014. 79 f. Dissertação (Mestrado em Ciências Florestais no 
Centro de Ciências Agrárias) - Universidade Federal do Espírito Santo, Jerônimo Monteiro - ES, 2014.

KING J. M. et al. Environmental flow assessments for rivers: Manual for the Building Block Methodology. WRC Report, n. TT 354/08. Cape Town. 2008. 364p.

LEMOS, A. F. Avaliação de metodologias de regionalização de vazões mínimas de referência para a bacia do rio São Francisco, à montante do reservatório de Três Marias. 2006. 85 p. Dissertação (Mestrado em Engenharia Agrícola) Universidade Federal de Viçosa, Viçosa, 2006.

LEVINE, D. M. et al. Estatística - teoria e aplicações: usando o Microsoft Excel em português. Rio de Janeiro: LTC, 2005.

MACIEL, A. L. et al. Uso conflitante da terra nas áreas de preservação permanente ao longo dos rios da bacia rio Santo Antônio - MG utilizando SIG. In XXII Simpósio Brasileiro de Recursos Hídricos, 2017, Florianópolis- SC.

MELO, M. S. Avaliação de potencial hidrelétrico com aplicação de sistema de informações geográficas. 2013. 230 f. Tese (Doutorado em geociências aplicadas) - Instituto de Geociências da Universidade de Brasília, Brasília, 2013.

MORIASI, D. N. et al. Model evaluation guidelines for systematic quantification of accuracy in watershed simulations. Transactions of the ASABE, v. 50, n. 3, p. 885-900. 2007.

NAGHETTINI, M.; PINTO, E. J. A. Hidrologia estatística. 1.ed. Belo Horizonte: CPRM, 552p. 2007.

NOVAES, L. F. Modelo para quantificação da disponibilidade hídrica na bacia do Paracatu. 2005. 116 p. Tese (Mestre em Engenharia Agrícola) - Universidade Federal de Viçosa, Viçosa, 2005.

OLIVEIRA, V. A. Regionalização de vazões nas regiões das unidades de planejamento e gestão de recursos hídricos GD1 e GD2, Minas Gerais. 2013. 103 f. Dissertação (Mestrado em Recursos Hídricos em Sistemas Agrícolas) Universidade Federal de Lavras, Lavras, 2013.

PEREIRA, L. A. Regionalização de vazões de permanência aplicado na região hidrográfica no Uruguai utilizando o programa SisCoRV. 2012. 118 f. Trabalho de Conclusão (Bacharel em Engenheiro Ambiental) - Faculdade de Engenharia e Arquitetura da Universidade de Passo Fundo, Passo Fundo, 2012.

PINTO, J. A. O. Avaliação de métodos para a regionalização de curvas de permanência de vazões para a bacia do rio das Velhas. 2006. 242 f. Dissertação (Mestrado em Saneamento, Meio Ambiente e Recursos Hídrico) - Universidade Federal de Minas Gerais, Belo Horizonte, 2006.

PRUSKI, F. F. et al. Estrapolação de equações de regionalização de vazões mínimas: Alternativas para atenuar os riscos. Water Resources and Irrigation Management, Campina Grande, PB, v.1, n.1, p.51-59, 2012.

PYRCE, R. Hydrological low flow indices and their uses. Watershed Science Centre, n. 4, 37 p., Agosto, 2004.

SANTOS, F. A. A. et al. Avaliação do uso de dados de precipitação gerados pelo $\mathrm{CPC} / \mathrm{NCEP}$ na modelagem hidrológica em uma região hidrológica do rio 
Araguaia. In XVII Simpósio Brasileiro de Sensoriamento Remoto, 2015, João Pessoa, PB.

SOUZA, R. M.; SANTOS, I. Área elementar representativa da bacia hidrográfica do altíssimo rio Negro, região sul-brasileira. In: XX Simpósio Brasileiro de Recursos Hídricos. Bento Gonçalves-RS, 2013.

TUCCI, C. E. M. Regionalização de vazões. 1. ed. Porto Alegre: UFRGS, 2002. $256 p$.

VESTENA, L. R. et al. Vazão ecológica e disponibilidade hídrica na bacia das Pedras, Guarapuava-PR. Ambi-Agua, Taubaté, v. 7, n. 3, p. 212-227, 2012.

VIEIRA, G. C. et al. Delimitação da Área de Proteção Natural dos Cursos Hídricos na Bacia do Rio Santa Bárbara - MG. In XXII Simpósio Brasileiro de Recursos Hídricos, 2017, Florianópolis- SC. 